\title{
Leadership and innovations in small and medium enterprises
}

\author{
Olga Yamova \\ Tyumen Industrial University \\ Volodarskogo street 38, 625000 Tyumen \\ Russian Federation \\ e-mail: helgaaf@mail.ru
}

\begin{abstract}
Leadership has always been connected to innovations and innovative behavior. Making right decisions, coming up with novel concepts and conquering the market niches has been the key element of successful entrepreneurship since the times of the inception of the ideas of Schumpeter and the "Blue Ocean" Strategy.

Small and medium enterprises (SMEs) often become the hub of the innovations. Most recently, there are startups, like the ones that constitute the essence of Silicon Valley innovational space, that push forward progress and novel approaches in business and economics.

This paper focuses on leadership and innovations using the case study of small and medium enterprises. It revises some relevant literature and makes several important implications about the role and the importance of innovations in SMEs that are being the leaders of technological progress, economic development and entrepreneurial activity worldwide. We argue that leadership in small and medium enterprises equals innovations and introducing innovations as such. The leading SMEs are often the most innovative ones.
\end{abstract}

\section{Introduction}

Quite often, one would pose question like the following: Does an innovation mean a business or a firm coming up with new products goods or services? What factors determine or affect the innovativeness of the business?

Over the years, different companies that were previously market leaders and had different products among the market leaders in their particular categories, decline and fall behind newer companies. In the early 2000s, companies, such as Nokia and Motorola were dominant players in the mobile telecommunication handsets, controlling the larger market share (Tellis, 2013). Tellis (2013) further observed that while these companies continued releasing new products, they ultimately ceded the market leadership positions to emerging firms in the sector such as Apple, Blackberry, and Samsung among others. In other industries, firms, such as Kodak, that controlled a large market share of the industries in which they operated, rapidly declined and struggled to remain competitive because they were not responsive to changes in the market or the operating environment (Hiltzik, 2011). These cases demonstrate that innovation goes over and above releasing new products and services and is important for firms and national economies alike.

Innovation is a very broad term and takes different forms in organizations. According to Bayarçelik et al. (2014), Kalyugina et al. (2015), Ehrenberger et al. (2015), Scuotto et al. (2017), Niño-Amézquita et al. (2017), or Naushad et al. (2018), innovation takes different forms; new product or changes in product properties, change in service delivery processes, changes in marketing methods, or other changes in an organization or external relations. Innovations can even be found in academic publishing when some more innovative researchers can use various tools to beat competition (see e.g. Molchanova et al. 2017; or Batkovskiy et al. 2018). Moreover, Koudelková and Svobodová (2014) point out that knowledge becomes the main determinant of innovations.

In agreement, Yeo and Saboori-Deilami (2017), Orlova et al. (2018), and Ahn et al. (2018) define innovation as a process of fostering competitiveness for a business by encouraging responsiveness of the business or as an endeavor of a business to achieve and retain first move advantage through continuous research and development to facilitate this process. Evidently, innovation is an essential ingredient of business and national economic growth and success, and it involves taking different actions in response to changes in the market such as technological changes, changes in customer tastes and preferences, or competitor activities. According to Bayarçelik et al. (2014) the operating environment of businesses is more dynamic and is characterized by intense rivalry, shorter product lifecycles, and rapid technological changes that necessitate commensurate changes in the business to keep abreast with the changes in the operating environment. For a business to be innovative, it is important for the management to identify and understand the different factors, such as finances, technological changes, competitor activities, and firm size, among others, that determine innovation or the level of innovation among others.

This paper focuses on the leadership and innovations in small and medium enterprises. We tackles such issues as the determinants of innovations, nature and type of innovations, as well as ways and approaches to measure innovations and innovation activity. 


\section{Determinants of innovations and leadership in Small and Medium Enterprises (SMEs)}

A wide range of factors affect or determine or have an impact on the innovativeness of a business because they can foster or impede the ability of a business to be innovative. The financial position and resources of SMEs is one of the main determinants of their innovativeness. According to Bayarçelik et al. (2014) the size of a business is a major determinant of the ability to innovate and to diffuse innovativeness because the larger the size of a SME, the more difficult it is to diffuse or encourage innovation within the organization. In another study Hadhri, Arvanitis, and M'Henni (2016) ascertained that among firms that fall outside the SME classification, larger firms are likely to be more innovative compared to smaller firms. As such, while for SMEs the size of the firm may be a determinant of the ability to innovate and diffuse the same, the study by Hadhri et al. (2016) indicates that it is possible for large SMEs to be equally or more innovative than the smaller ones, which implies that while size of the firm may be a determinant of innovativeness, it is may not be very significant.

Competitor activities are also a major determinant of the innovativeness of a business. According to Hadhri et al. (2016) increased competition and threat of new entrants is likely to drive incumbent firms to be more innovative in an endeavor to maintain their position in the industry. More specifically, in the study, Hadhri et al. (2016) observed that the incumbent will be more innovative in an endeavor to patent technologies that will ensure that the business retains its monopolistic advantage over new entrants. Indeed, according to Bayarçelik et al. (2014) competitor activities, as well as the competitive advantage of a firm enjoys, are major determinants of the innovativeness of SMEs because they will seek to protect their position in an industry against an influx of competing firms or competition from existing firms.

Government policies and activities are also major determinants of the innovativeness of SMEs. According to Zemplinerová and Hromádková (2012) government funding, subsidies, and other similar activities could motivate firms to be innovative, and the absence of such incentives, subsidies or similar measures may impede the innovativeness of SMEs. Indeed, Zemplinerová and Hromádková (2012 p.490) observed that public subsidy thus mitigates high, uninsurable risk of decisions to innovate. In their study, Hadhri et al. (2016) made similar observations that the government support or lack thereof for research and development will encourage or discourage innovativeness among SMEs. Moreover, the government should formulate and implement legislations, regulations, and other policies that support and regulate the provision of support to SMEs. It is therefore imperative for governments to provide different types of incentives or subsidies that will support research and development, which is a key driver of the innovativeness of SMEs and ensure that the same is grounded in a strong legal or legislative framework.

Another major determinant of the innovativeness of SMEs is customer tastes and preferences. According to Bayarçelik et al. (2014), customers particularly drive the innovativeness of businesses because a business has to keep abreast of all the changes in tastes and preferences. If a business does not produce products goods or services that fulfill or meet the tastes and preferences of customers, it will most likely fail in the long-term. The net effect of the changes in tastes and preferences of customers, considered together with other factors, collectively determines the innovativeness of SMEs. Other factors that determine or affect the innovativeness of a business include economic factors, technological factors, institutional factors, cultural factors, learning capability, management skills and competencies, and market orientation (Bayarçelik et al., 2014; Hadhri et al., 2016). Evidently, there are many factors that determine the level of innovativeness among SMEs, and it is therefore important for the management of SMEs to ascertain the factors that apply to each particular firm and take action to foster innovation and in so doing foster the competitiveness of SMEs.

\section{Nature and type of innovations}

The nature or form of innovation is highly diversified; it involves changes in product properties or features, changes in processes, or other improvements in different aspects or elements of business operations that make a business more responsive to changes in the operating environment. For an SME, innovation may involve coming up with a new product or improving on an existing product to make it meet and exceed customer expectations or in response to changes in the tastes and preferences of a business. In this form, innovation could involve improvements in product features, changes in packaging, or totally coming up with a product, which according to Yeo and Saboori-Deilami (2017) may be driven by the pursuit of improved return on investment, response to changes in customer tastes and preferences, or other factors that necessitate the development of a new product or improvements in an existing product. For example, Microsoft Corporation, over the years, instead of doing away with the Windows operating system or the Microsoft Office Suite, has continuously improved on earlier versions to make the product more responsive to the changes in the market or the changes in customers' tastes and preferences. Indeed, according to Bayarçelik et al. (2014) on type of innovation includes the development of new products or changes in product properties, which makes the product more suitable or beneficial to customers. Releasing a new product or improving an existing product is the primary form of innovation, and in so doing, a business is able to ensure that it meets and exceeds the expectations of its customers. 
Furthermore, innovation may take the form of changes in the operating processes or procedures of the business, aimed at improving operational efficiency and effectiveness of the business. For example, if a firm, engaged in manufacturing operations, over a period of time, ascertains that the process currently used is inefficient, it could develop and implement a new process that will improve time taken, output, or reduce wastage among other possible indicators of the effectiveness of a business' processes. According to Bayarçelik et al. (2014) innovativeness goes over and above changes in the product features, or benefits to include other changes, such as the change in service delivery processes or changes in the marketing methods, or other changes in an organization or external relations. Primarily, a firm will first look inward in an endeavor to make changes or be more innovative, and will change its products or processes, which are all aimed at fostering organizational innovativeness.

Indeed, in concurrence, in their study, Zemplinerová and Hromádková (2012) identified similar types of innovation; product, marketing, process, and organization innovation; with the most prevalent or common type of innovation being process, followed product, then organizational, and finally, marketing innovation. The findings implied that most SMEs would be more likely to change processes, come up with new products, or change organizational aspects in their endeavor to be innovative. Zemplinerová (2010) made similar observations, product, process, and organizational changes are likely to constitute a large portion of the innovative activities of firms. As such, all the activities in an organization, including as pointed above, the changes in the product features or benefits, such as packaging or changes in ingredients; reviews and changes of organizational processes, and or changes in other aspects of organizational operations, all constitute innovativeness, which are all the activities that are implemented to improve organizational competitiveness.

\section{Measuring innovativeness and innovations}

It is important for a business to keep track and measure innovativeness to ascertain if activities undertaken towards this end actually achieve the desired goals and objectives. There are many measures or approaches that SMEs can use to measure innovativeness, such as the number of new products, the number of improvements, inventions, revenues and profitability changes, and other similar changes in an organization that improve operational efficiency or the general competitiveness of the business. Indeed, according to Denti (2013), SMEs or firms, can use new products or product improvements, the number of patent applications, inventions disclosures and or suggestions, and process innovations within an organization among others. For example, in an endeavor to track innovativeness, a company such as Google may track the number of patents for new products or technologies filed with the relevant offices, and years in which the business files more patents, the levels of innovation can be deemed to be high, while in years that the number of patents are low, innovativeness can be considered to be lower.

In this paper, we are employing an empirical model of determining innovations in SMEs. Following the evaluation of the theory of innovations, collection of a large amount of data and preparation of the dataset, we will now proceed to description of the model and later to its estimation. The data comes from the sample of 651 enterprises (European SMEs). The linear econometric model used in our paper is a multivariate statistical model of the form:

$$
Y=\beta_{0}+\beta_{1} X_{1}+\ldots+\beta_{n} X_{k}+\varepsilon_{i}
$$

where $\mathrm{Y}$ is the dependent variable defined as the existence of innovations in SMEs (measured by the existence of patents, certificates, etc.), $\mathrm{X}_{1}, \ldots, \mathrm{X}_{\mathrm{k}}$ are the explanatory variables and $\varepsilon$ is the error term. The results of the model are presented in Table 1.

Table 1. Enterprise innovation: an empirical model estimation

\begin{tabular}{|l|c|}
\hline \multicolumn{2}{|c|}{ Innovations in SMEs } \\
\hline Equipment age & $-0.0583 * *$ \\
\hline & $(0.0282)$ \\
\hline Competitors & $0.0417 * *$ \\
\hline & $(0.017)$ \\
\hline New technologies & $0.325 * * *$ \\
\hline & $(0.072)$ \\
\hline Diversification & $0.390 * *$ \\
\hline & $(0.093)$ \\
\hline Quality & $0.447 * * *$ \\
\hline
\end{tabular}




\begin{tabular}{|l|c|}
\hline & $(0.066)$ \\
\hline Marketing & $0.324 * * *$ \\
\hline & $(0.084)$ \\
\hline Own R\&D & $0.420 * * *$ \\
\hline & $(0.073)$ \\
\hline Market barriers & $-0.306 * *$ \\
\hline & $(0.093)$ \\
\hline Constant & $2.294 * * *$ \\
\hline & $(0.1592)$ \\
\hline Observations & 651 \\
\hline R-squared & 0.49 \\
\hline
\end{tabular}

Source: Own results

Note: *, **, and *** are significance intervals (above 10\%, between 5 and $10 \%$ and below 5\%).

Overall, one can see that factors as the new technologies, own R\&D, marketing and quality all contribute to the level of innovations in SMEs. The leaders simply have to invest in their own development in order to keep their niches on the markets.

\section{Conclusions}

All in all, one can clearly see that innovations represent a very broad term that encompasses changes or improvements of products, processes, procedures, and other aspects of an organization's operations in order to be more competitive.

In addition, it becomes apparent that innovation has become an integral part of the endeavors of businesses to be competitive especially in the face of increased competition, rapid changes in technology, and dynamic customer tastes and preferences. It is therefore imperative for business managers in the SME sector to understand the key drivers of innovativeness and put in place measures of innovativeness in their firms in order to be more competitive in the long-term.

One can conclude that modern business leaders need to be innovative in order to gain their share of market and to achieve success. Small and medium enterprises are the best subject for developing and fostering innovative ideas and by doing so they can grow into the leading companies of tomorrow, just like Facebook or Google did at the Silicon Valley thanks to their focus on innovations.

These lessons should be learned by all small and medium enterprises seeking success and acknowledgement. Without innovations, an enterprise would not achieve any considerable success.

\section{References}

Ahn S, Yoon J, Kim Y (2018) The innovation activities of small and medium-sized enterprises and their growth: quantile regression analysis and structural equation modeling. The Journal of Technology Transfer 43(2):316342. doi: 10.1007/s10961-017-9570-3

Batkovskiy AM, Kalachikhin PA, Semenova EG, Telnov YF, Fomina AV, Balashov VM (2018) Configuration of enterprise networks. Enterpreneurship and Sustainability Issues 6(1):311-328. doi: 10.9770/jesi.2018.6.1(19)

Bayarçelik, E. B., Taşel, F., \& Apak, S. (2014). A research on determining innovation factors for SMEs. Procedia-Social and Behavioral Sciences 150:202-211. doi: 10.1016/j.sbspro.2014.09.032

Denti, L. (2013). Measuring Innovation part 1: Frequently Used Indicators. Innovation Psychology.

Ehrenberger M, Koudelkova P, Strielkowski W (2015) Factors influencing innovation in small and medium enterprises in the Czech Republic. Periodica Polytechnica Social and Management Sciences 23(2):73-83. doi: 10.3311/PPso.7737

Hadhri W, Arvanitis R, M'Henni H (2016) Determinants of innovation activities in small and open economies: the Lebanese business sector. Journal of Innovation Economics \& Management (3):77-107. doi: 10.3917/jie.021.0077

Hiltzik M (2011) Kodak's long fade to black. Los Angeles Times, 4, 12. 
Kalyugina S, Strielkowski W, Ushvitsky L, Astachova E (2015) Sustainable and secure development: facet of personal financial issues. Journal of Security \& Sustainability Issues 5(2):297-304. doi: 10.9770/jssi.2015.5.2(14)

Koudelková P, Svobodová P (2014) Knowledge creation \& sharing as essential determinants of SMEs innovation. International Economics Letters 3(1): 12-20. doi: 10.24984/iel.2014.3.1.3

Molchanova A, Chunikhina N, Strielkowski W (2017) Innovations and academic publishing: who will cast the first stone? Marketing and Management of Innovations 4:40-48. doi: 10.21272/mmi.2017.4-03

Naushad M, Faridi M R, Syed A M (2018) Economic development of community by entrepreneurship: an investigation of the entrepreneurial intent and the institutional support to the local community in Al-Kharj region. Entrepreneurship and Sustainability Issues 5(4):899-913. doi:10.9770/jesi.2018.5.4(14)

Niño-Amézquita J, Dubrovsky V, Jankurová A (2017) Innovations and competitiveness in regional development: a comparison of Latin America, Europe, and China. Czech Journal of Social Sciences, Business and Economics 6(1):28-36. doi: 10.24984/cjssbe.2017.6.1.4

Orlova L, Gagarinskaya G, Gorbunova Y, Kalmykova O (2018) Start-ups in the field of social and economic development of the region: a cognitive model. Entrepreneurship and Sustainability Issues 5(4):795-811. doi:10.9770/jesi.2018.5.4(7)

Scuotto V, Del Giudice M, Bresciani S, Meissner D (2017) Knowledge-driven preferences in informal inbound open innovation modes. An explorative view on small to medium enterprises. Journal of Knowledge Management 21(3):640-655. doi: 10.1108/JKM-10-2016-0465

Tellis G (2013) Creating a culture for unrelenting innovation. MWorld 12(2):38-41.

Yeo C, Saboori-Deilami V (2017) Strategic challenges of outsourcing innovation in global market. Asia Pacific Journal of Innovation and Entrepreneurship 11(1):5-16. doi: 10.1108/APJIE-04-2017-017

Zemplinerova A (2010) Innovation activity of firms and competition. Politická Ekonomie 58(6):747-760.

Zemplinerová A, Hromádková E (2012) Determinants of firm’s innovation. Prague Economic Papers 21(4):487503. doi: $10.18267 /$ j.pep.436 